\title{
Autoantibodies to B Lymphocytes in a Patient with Hypoimmunoglobulinemia
}

\author{
CHARACTERIZATION AND PATHOGENIC ROLE
}

\author{
Thomas Tursz, Jean-Louis Preud'homme, Sylvaine Labaume, \\ Claude Matuchansky, and Maxime SeligmanN
}

\begin{abstract}
From the Laboratory of Immunochemistry and Immunopathology (Institut National de la Santé et de la Recherche Médicale U 108) Research Institute on Blood Diseases, Hôpital Saint-Louis, 75475 Paris Cedex 10 and the Clinique Gastro-Entérologique, Hôpital Saint-Lazare, 75010 Paris, France
\end{abstract}

\begin{abstract}
A B S TRACT In a young woman with ulcerative colitis, hypoimmunoglobulinemia, and humoral immunodeficiency, lymphocyte counts vary between 600 and 1,000 per $\mathrm{mm}^{3}$ with $0.5-1.5 \%$ bone marrowderived (B) cells and 98-99\% thymus-derived (T) cells. Anti-lymphocyte antibodies were detected by immunofluorescence and by microlymphocytotoxicity with increased reactivity at $+4^{\circ} \mathrm{C}$. They belonged to the IgM class and were polyclonal. Studies performed with various normal lymphocyte subpopulations, several lymphoblastoid cell lines and lymphocytes from immunodeficiency patients showed that these antibodies reacted with $\mathrm{B}$ cells. The corresponding antigen(s) is distinct from membrane-bound immunoglobulins, is not an alloantigen, and is probably unrelated to the la-like molecules. Pokeweed mitogen stimulated B cells appear to lose this antigen. Cells from various lymphoproliferative disorders were tested. T-derived and "non T-non-B" leukemic cells did not react with the antibody. Malignant cells from B-derived lymphomas and prolymphocytic leukemias were reactive. The incidence of positivity of the leukemic cells among patients with common B chronic lymphocytic leukemia was surprisingly low (one-third of the patients).

The autoantibody nature of the anti-B-cell antibodies and their pathogenic role in the genesis of

This work was presented, in part, at the 3rd European Immunology Meeting in Copenhagen, Denmark in August 1976 as Abstract $\mathrm{P} 128$.

Dr. Tursz's present address is Service de Médecine A, Institut Gustave Roussy, 94800 Villejuif, France. Dr. Matuchansky's present address is Service de Gastro-Entérologie, Hotel-Dieu, 86000 Poitiers, France.

Received for publication 14 February 1977.
\end{abstract}

the patient's hypoimmunoglobulinemia was demonstrated by the effect of removal of antibodies by massive plasmaphereses which were followed by a dramatic and transitory increase of B-cell figures. Whereas most primary immunodeficiency syndromes appear to result from an arrest in the differentiation capabilities of immunologically competent cells, autoantibodies to circulating B lymphocytes may be incriminated in the pathogenesis of some cases of hypogammaglobulinemia.

\section{INTRODUCTION}

Most primary immunodeficiency (ID) ${ }^{1}$ syndromes appear to result from an arrest in the differentiation capabilities of immunologically competent cells at various stages (1). However other mechanisms such as specific killing of normally maturing lymphocytes by lymphocytotoxic autoantibodies could be incriminated in the pathogenesis of some ID. Lymphocytotoxins have been recently reported in a variety of human diseases, including systemic lupus erythematosus and inflammatory bowel diseases $(2,3)$. The data on the occurrence of such anti-lymphocyte antibodies in patients with ID are very scarce $(4,5)$. In the hitherto reported cases neither a definite anti-B (bone marrow-derived) or anti-T (thymus-derived) specificity nor a clear relationship with immunodepression have been established.

\footnotetext{
${ }^{1}$ Abbreviations used in this paper: CLL, chronic lymphocytic leukemia; ID, immunodeficiency; IF, immunofluorescence; PBL, peripheral blood lymphocytes; PHA, phytohemagglutinin; PWM, pokeweed mitogen; SIg, surface immunoglobulins.
} 
We have found, in the serum of a patient with panhypoimmunoglobulinemia and a profound decrease in the number of circulating $B$ cells, antilymphocytic antibodies with clear specificity for B lymphocytes which appear to play a role in the pathogenesis of the B-cell deficiency. This antibody will be referred below as D. S. antibody.

\section{METHODS}

Case report and immunological evaluation of the patient. Patient D.S. is a Portuguese woman born in 1943 whose family clinical history was not contributive. She was entirely well until 1970 when she developed recurrent bronchitis and diarrhea. In 1972, she was found to have a moderately enlarged spleen, bronchectasia, and ulcerative colitis. In 1975 , very serious bronchopulmonary infections occurred with cardiac failure, and the severity of the ulcerative colitis led to total colectomy. A detailed report of the intestinal disease will be published elsewhere. ${ }^{2}$

Serum immunoglobulin (Ig) levels were repeatedly measured and varied between 2 and $5 \mathrm{mg} / \mathrm{ml}$ for IgG, 0.3 and 0.7 $\mathrm{mg} / \mathrm{ml}$ for IgM, and 0.1 and $0.15 \mathrm{mg} / \mathrm{ml}$ for IgA. The study of humoral immunity showed a moderate and dissociated impairment. The level of anti-B isohemagglutinins was normal. No antipoliomyelitis antibodies were found. The titers of antibodies to tetanus toxoid remained low after challenge whereas the patient responded normally to diphtheria toxoid. Some plasma cells containing IgA, IgM, and IgG were found in the intestinal mucosa and germinal centers were present in the mesenteric lymph nodes obtained at colectomy. The patient was unresponsive to intradermal injections of streptokinase-streptodornase and tuberculin, but the intradermal reaction to candidin was positive and she exhibited a normal response after sensitization to dinitrochlorobenzene. Peripheral blood lymphocytes (PBL) responded normally to in vitro stimulation by phytohemagglutinin (PHA), pokeweed mitogen (PWM), and allogeneic lymphocytes.

PBL counts varied between 600 and 1,000 per $\mathrm{mm}^{3}$. Repeated studies of surface immunoglobulins (SIg), aggregated IgG binding, and formation of spontaneous rosettes with sheep erythrocytes were performed according to methods described in detail elsewhere (6) and showed values of 0.5 to $1.5 \%$ for B cells and 98-99\% for T lymphocytes, without "null" lymphocytes unidentified by the surface markers.

An IgM type-positive Coombs test was transitory observed. Antinuclear factors were negative and serum total hemolytic complement was normal.

Lymphocytotoxicity. Microlymphocytotoxicity assays were performed according to Terasaki et al. (7) with the following minor modifications: lymphocytes were incubated at $+4^{\circ} \mathrm{C}$ for $30 \mathrm{~min}$ with serum D.S. followed by an incubation at $37^{\circ} \mathrm{C}$ for $60 \mathrm{~min}$ with rabbit fresh serum as a source of complement.

Immunofluorescence (IF) studies. The reactivity of D.S. antibodies with living cells was studied by membrane IF by both the direct and indirect techniques. As reported below, the D.S. antibodies belong to the IgM class and react at the B-cell surface independently of SIg. Indirect staining could therefore be performed either on cells lacking SIgM or after capping of SIg by anti-Ig reagents. In the latter experiments, the cells were first stained with fluorescein

${ }^{2}$ Matuchansky, C., et al. Manuscript in preparation. conjugated antisera to human Ig, either polyvalent or monospecific for $\mu$ chains, then incubated at $37^{\circ} \mathrm{C}$ for $60 \mathrm{~min}$ to induce capping, and cooled down to $0^{\circ} \mathrm{C}$. The following steps were performed at $+4^{\circ} \mathrm{C}$ : incubation with D.S. serum, washing, and further incubation with a rhodamine-conjugated anti- $\mu$ reagent. The cells were examined with a Leitz Orthoplan fluorescence microscope (E. Leitz, Inc., Rockleigh, N.J.) equipped with a Ploem's vertical illuminator with alternative illumination using filter combinations specific for fluorescein and rhodamine. The procedures used to prepare mononuclear cell suspensions from peripheral blood, tonsils, or thymus, the methods used for IF, the characteristics and specificity controls of conjugated IgG or $\mathrm{F}\left(\mathrm{ab}^{\prime}\right) 2$ fragments of polyvalent or monospecific antisera to Ig chains have been previously described in detail (8). Since the very low IgM level in serum D.S. precluded its purification, a $33 \%$ ammonium sulfate precipitate from D.S. serum was conjugated to fluorescein and used for direct IF. This conjugate had an OD ratio (OD $280 \mathrm{~nm} / \mathrm{OD}$ $495 \mathrm{~nm}$ ) of 1.2 and a protein concentration of 0.785 $\mathrm{mg} / \mathrm{ml}$. Most experiments were performed with a concentration of $0.1-0.2 \mathrm{mg} / \mathrm{ml}$ and similar results were obtained with further dilutions up to $0.025 \mathrm{mg} / \mathrm{ml}$. Since this conjugate was prone to nonspecific staining, it was kept frozen in small portions and IF studies were performed within a few days after thawing. Direct or indirect staining with D.S. antibody was also performed in combination with usual lymphocyte markers such as SIg, IgG aggregate binding, and E-rosette formation.

Other methods. T-lymphocyte-enriched populations were obtained by passing PBL through nylon-wool columns and $B$-cell-enriched populations by elimination of $E$ rosette forming cells by Ficoll centrifugation.

PBL stimulated by PHA and PWM were also studied with the D.S. antibody. Proliferative responses were controlled by $\left[{ }^{3} \mathrm{H}\right]$ thymidine incorporation. Cultured lymphoblastoid cell lines and human fibroblasts were kindly provided by Dr. M. Fellous.

Extensive plasmaphereses were achieved with a continuous flow blood cell IBM separator (IBM Corp., White Plains, N.Y.).

\section{RESULTS}

Demonstration and characterization of D.S. antibodies. Using microlymphocytotoxicity assays, D.S. serum was shown to react with lymphocytes from all 57 normal individuals tested, from both sexes and with various HLA phenotypes. The percentage of killed cells ranged from 15 to $25 \%$ and the serum titer reached $1 / 128$. The lymphocytotoxic activity was detectable at $37^{\circ} \mathrm{C}$ and at room temperature and was moderately increased at $4^{\circ} \mathrm{C}$. In direct IF studies, D.S. conjugate stained 12-20\% (mean 14.5\%) PBL from all 20 normal donors tested.

In indirect IF tests performed after capping of SIg, D.S. antibodies were revealed on target lymphocytes by specific anti- $\mu$ conjugates but not by conjugated antisera to the other heavy chain classes. Furthermore the pure IgG fraction obtained from D.S. serum by diethylaminoethyl cellulose chromatography and conjugated to fluorescein yielded negative results. Thus, D.S. anti-lymphocyte antibody was shown to belong exclusively to the IgM class. That these IgM 
antibodies possessed both light chain types was established by indirect IF experiments with the proliferating lymphocytes from a patient with heavy $\gamma$ chain disease which bore only surface $\gamma$ chains and was devoid of light chains. D.S. antibodies could be stained on these lymphocytes by both anti- $\kappa$ and anti- $\lambda$ conjugated antisera as well as by the anti- $\mu$ conjugate. D.S. antibodies were thus characterized as polyclonal IgM molecules.

Anti-B-cell specificity. The percentage of normal PBL reactive with D.S. antibody was similar to the expected figures for B cells. Analogous percentages of SIg-bearing and D.S.-positive lymphocytes were found within unseparated PBL, PBL enriched for B cells or for $\mathrm{T}$ cells, tonsil cells, and thymocytes (Table I). The PBL from three patients with sexlinked or variable immunodeficiencies and without any detectable B cells were not stained by DS conjugate. The T-derived lymphoblastoid cell line MOLT-4 did not react with D.S. conjugate whereas three B lymphoblastoid lines (Daudi, Raji, and T-51) were heavily labeled. D.S. antibodies could be completely adsorbed out on Raji cells.

Experiments combining direct IF staining with D.S. conjugate and $\mathrm{E}$ rosette formation were performed on PBL from three normal donors (Table II). A complete exclusion of the two markers was found, except for $1 \%$ of cells which were positive for both. When the same experiment was performed with tonsil cells, E rosette + D.S. + cells were not observed whereas $95 \%$ of the non-E rosetting cells were labeled by D.S. conjugate.

TABLE I

Percentage of Normal Lymphocytes Stained by Conjugated D. S. Antibody Compared to Usual Lymphocyte Markers

\begin{tabular}{lccccc}
\hline $\begin{array}{c}\text { Lymphocyte } \\
\text { population }\end{array}$ & $\begin{array}{c}\text { Exper- } \\
\text { iment } \\
\text { number }\end{array}$ & $\begin{array}{c}\text { D. S. } \\
\text { con- } \\
\text { jugate }\end{array}$ & SIg & $\begin{array}{c}\text { Ag- } \\
\text { gregated } \\
\text { IgG }\end{array}$ & E rosettes \\
\hline PBL & 1 & 13 & 13 & 15 & 68 \\
Unfractionated & 2 & 11 & 11 & 16 & 64 \\
& 3 & 24 & 18 & & \\
T enriched* & 4 & 13 & 12 & & \\
& 1 & 0.5 & 1 & & \\
B enriched $¥$ & 2 & 0.5 & 0.5 & & \\
Tonsil & 1 & 74 & 72 & & \\
& 2 & 65 & 65 & & \\
Thymus & 1 & 39 & & & 53 \\
& 2 & 46 & 52 & & 47 \\
\hline
\end{tabular}

* After passage through nylon-wool column.

$\downarrow$ After depletion of E-rosetting cells by Ficoll centrifugation.
TABLE II

Experiments Combining Direct Staining with D. S. Conjugate and E-Rosette Formation

\begin{tabular}{|c|c|c|c|c|c|c|}
\hline \multirow[b]{2}{*}{$\begin{array}{c}\text { Exper- } \\
\text { iment } \\
\text { number }\end{array}$} & \multicolumn{2}{|c|}{$\begin{array}{l}\text { Separate } \\
\text { studies }\end{array}$} & \multicolumn{4}{|c|}{ Combined study } \\
\hline & $\begin{array}{c}E \\
\text { rosette } \\
\text { alone }\end{array}$ & $\begin{array}{l}\text { D. S. } \\
\text { alone }\end{array}$ & $\begin{array}{c}\mathbf{E} \\
\text { rosette+ } \\
\text { D. S. - }\end{array}$ & $\begin{array}{c}\mathbf{E} \\
\text { rosette- } \\
\text { D. S.+ }\end{array}$ & $\begin{array}{c}E \\
\text { rosette- } \\
\text { D. S.- }\end{array}$ & $\begin{array}{c}\text { E } \\
\text { rosette+ } \\
\text { D. S.+ }\end{array}$ \\
\hline & \multicolumn{6}{|c|}{ \% lymphocytes } \\
\hline 1 & ND & ND & 52 & 16 & 31 & 1 \\
\hline 2 & 68 & 13 & 56 & 11 & 32 & 1 \\
\hline 3 & 64 & 11 & 58 & 11 & 30 & 1 \\
\hline
\end{tabular}

Double labeling of normal PBL with a mixture of anti- $\kappa$ and anti- $\lambda$ antisera conjugated to rhodamine and with fluorescein conjugated D.S. antibodies showed that the vast majority but not all of the D.S. reactive lymphocytes bore SIg. Conversely a small subset of SIg-bearing cells appeared to lack the antigenic determinant(s) reacting with D.S. antibody. In these experiments, of 100 fluorescent cells $81 \%$ were SIg + D.S.+, $4 \%$ SIg - D.S.+, and 15\% SIg + D.S.-. Capping of SIg induced on normal or leukemic lymphocytes by monospecific anti- $\mu$ or anti- $\delta$ rhodamine conjugates did not result in a redistribution of the membrane antigen(s) revealed by D.S. antibody. Indeed restaining by fluorescein D.S. conjugate in noncapping conditions showed a diffuse distribution. Similarly a diffuse staining pattern of SIgM or SIgD was observed on cells after capping induced by the fluorescein D.S. conjugate.

Double labeling experiments with conjugated heataggregated human IgG and D.S. antibodies showed that $97 \%$ of the fluorescing cells were double labeled with only $2 \%$ positive for the IgG aggregates and negative for D.S. and $1 \%$ stained by the D.S. conjugate and negative for IgG aggregates. It should be noted that D.S. antibody strongly inhibited the fixation of aggregated IgG but the reverse was not true.

Reactivity with cells from lymphoproliferative diseases. As shown in Table III, leukemic T-derived cells (9) and acute lymphoblastic leukemia cells were not reactive with D.S. antibody whereas proliferating B-derived cells from patients with lymphomas or $\gamma$-chain disease gave positive results. In contrast to these results and to the fact that most B lymphocytes from all normal individuals react with D.S. antibody, the incidence of B-derived chronic lymphocytic leukemia (CLL) with reactive leukemic cells was surprisingly low. In those negative B CLL cases which were further studied, the absence of the antigen(s) combining with D.S. antibody was confirmed by the unability of these leukemic cells 
TABLE III

Reactivity of D. S. Antibody with Cells from Lymphoproliferative Diseases (Direct IF and [or] Microcytotoxicity)

\begin{tabular}{lccc}
\hline \multicolumn{1}{c}{ Disease } & B or T nature & $\begin{array}{c}\text { Number } \\
\text { tested }\end{array}$ & $\begin{array}{c}\text { Number } \\
\text { reactive } \\
\text { with D. S. } \\
\text { antibody }\end{array}$ \\
\hline $\begin{array}{l}\text { T-derived CLL } \\
\begin{array}{l}\text { Acute lymphoblastic } \\
\text { leukemias }\end{array}\end{array}$ & T & 7 & 0 \\
$\begin{array}{l}\text { Burkitt's lymphoma with } \\
\text { leukemic presentation }\end{array}$ & non-T non-B & 4 & 0 \\
$\begin{array}{l}\text { Poorly differentiated } \\
\text { lymphocytic lymphoma }\end{array}$ & B & 1 & 1 \\
$\begin{array}{l}\gamma \text {-Heavy chain disease } \\
\begin{array}{l}\text { B-derived CLL } \\
\text { Common }\end{array}\end{array}$ & B & 3 & 3 \\
$\begin{array}{l}\text { Prolymphocytic } \\
\text { With serum mono- } \\
\text { clonal Ig }\end{array}$ & B & 2 & 2 \\
\hline
\end{tabular}

(similarly to T-derived leukemic cells and contrarily to D.S.-positive "proliferating cells") to absorb out D.S. antibodies. It should be noted that the proliferating cells from all four cases of prolymphocytic CLL (10) and three of four cases of CLL with a monoclonal Ig serum spike reacted with D.S. antibody, whereas positive results were obtained in only one-third of the common CLL cases. In all negative cases, the leukemic cells stained faintly for SIg; on the other hand many of the positive CLL cases were featured by high density SIg on the leukemic cells.

Reactivity with mitogen-stimulated lymphocytes. PHA and PWM stimulated lymphocytes from three normal donors were studied for SIg and reactivity with D.S. antibody by direct immunofluorescence. After a 4-day stimulation with PHA, the figures for SIg and for D.S. antigen-bearing cells were concomitantly decreased to $2 \%$. Conversely with PWMstimulated lymphocytes at day 4, 7-18\% (mean 13.5\%) of the cells bore SIg, whereas only $3-4 \%$ of the stimulated lymphocytes reacted with D.S. antibody. At day 7 of PWM stimulation, 2-5\% (mean 3.3\%) of the cells were still carrying SIg but the reactivity with D.S. antibody was no longer observed. PWM stimulated B cells thus appeared to lose D.S. antigen.

Reactivity with other tissues. D.S. antibody was found to react both by direct IF and by microcytotoxicity with normal human fibroblasts from all seven tested cultures. The adsorption of serum D.S. on human fibroblasts abolished its reactivity with B cells.
The anti-lymphocytic activity of D.S. antibody remained unaffected after adsorption of D.S. serum on erythrocytes from the patient herself and from donors with various phenotypes.

Effects of plasmaphereses on circulating B cells. A 6-h plasmapheresis was achieved with a continuous flow blood cell separator with permanent restitution of the plasmatic mass with stored normal plasma. This plasmapheresis allowed to pull out 5 liters of plasma, i.e., more than twice the patient's plasma volume. As shown on Fig. 1, this plasmapheresis was followed by a dramatic increase in the number of $B$ cells which reached normal figures on day 3 with a normal distribution for the various SIg classes and types. This rise was transitory since at day 6 the number of $B$ cells decreased again to previous levels. Concomitantly, the anti-B antibody, which was no more detectable in the serum sample obtained at the end of the plasmapheresis, was found again 1 day later and rose progressively back to the initial titer within 6 days.

13 days later the patient underwent a second plasmapheresis for only $4 \mathrm{~h}$. Similar but less striking effects were observed. The percentage of circulating B cells reached $5 \%$ at day 2 but decreased again to $1 \%$ at day 4. The antibody remained detectable at a low titer at the end of the second plasmapheresis and its rate of reappearance was faster than after the first plasmapheresis since it rose back to the titer of $1 / 128$ at day 3 .

\section{DISCUSSION}

The anti-lymphocyte antibodies which were detected by immunofluorescence and cytotoxicity in the serum of this patient with panhypoimmunoglobulinemia and a profound decrease in the number of circulating $B$ lymphocytes belonged to the IgM class and were polyclonal. Their cytotoxic activity in vitro was maximum

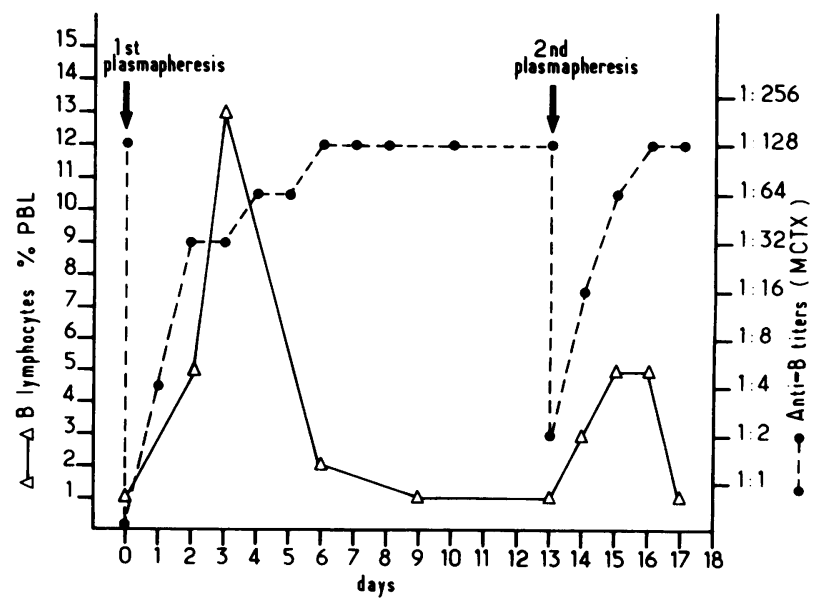

FIGURE 1 Effects of plasmaphereses on the percentage of B lymphocytes in the blood and on the titer of D.S. anti-B antibodies. MCTX, microcytotoxicity. 
at $+4^{\circ} \mathrm{C}$. The anti-B-cell specificity of these autoantibodies was established by double labeling experiments and by the study of normal lymphocyte subpopulations, lymphoblastoid cell lines, and cells from patients with ID or with lympho-proliferative diseases. However a small subset of circulating B cells ( $1 \%$ of PBL) appears to lack the corresponding antigen(s) which conversely may be present on a small subset ( $1 \%$ of $\mathrm{PBL}$ ) of cells expressing $\mathrm{T}$ markers.

The precise nature of the B-cell antigen(s) that react with D.S. antibodies remains unknown. These antigen(s) are clearly distinct from SIg since they were shown to cap independently and since D.S. antibodies react with Raji cells (which lack SIg) and fail to react with SIg-bearing PWM-stimulated lymphocytes. In view of their presence on the $B$ cells from all normal individuals so far tested, the antigenic determinant(s) revealed by D.S. antibodies appear to be distinct from the group of B-cell alloantigens which have close similarity to the Ia antigens of the mouse (11). Moreover they appear to be distinct from the common determinants of these Ia-like molecules revealed by various hetero-antisera $(12-14)$ since D.S. antibodies react with fibroblasts, do not react with cells from patients with "non-B-non-T" acute lymphoblastic leukemias, and fail to inhibit mixed lymphocyte reactions (in experiments kindly performed by Dr. Fradelizi).

The surprising lack of reactivity of D.S. antibodies with the proliferating cells from two-thirds of patients with common B CLL can probably not be explained on the basis of the arising of these leukemic clones from a negative B-cell subset since such a subset accounts for less than 5\% of normal B PBL. Whether this negative finding is related to the neoplastic nature of the CLL cells or to the various levels in the differentiation pathway of the B-cell line where proliferating clones from individual CLL patients appear to be blocked (6) is presently unknown. In this context, it is worth noting that the antigen(s) reacting with D.S. antibodies are expressed on only a minor proportion of SIg-bearing PWM-transformed B cells on the 4th day of culture and are no longer detectable on the 7th day. Thus, the B-cell antigen(s) reacting with D.S. antibodies are possibly expressed at only certain stages of B-cell differentiation.

Anti-lymphocyte antibodies have been rarely reported in patients with primary ID. A complementdependent lymphocytotoxic factor was demonstrated in the serum of a young boy with low serum IgM, impaired cellular immunity, absent immunologic memory, and episodic lymphopenia (4). In another boy with recurrent infections and deficiency of both cellular and humoral immunity, a high titer IgM antibody to IgG was found and was thought to be responsible for a non-HLA associated lymphocytotox- icity which was blocked by IgG (5). In patient D.S., it may be assumed that the antibody to B lymphocytes is an autoantibody and that it played a crucial role in the pathogenesis of hypoimmunoglobulinemia, since the withdrawal of this antibody by plasmapheresis was followed by a dramatic and transitory increase in the number of circulating $B$ lymphocytes. Since those B cells which escape the noxiousness of the autoantibodies are presumably able to differentiate normally, it is not surprising that in patient D.S. the very low figures for circulating B cells contrasted with a fair but not extremely profound hypoimmunoglobulinemia, a relatively moderate impairment of humoral immunity (with normal cellular immunity), the presence of germinal centers in the mesenteric lymph nodes, and grossly normal figures for plasma cells in the intestinal tract. Autoantibodies to B lymphocytes should be systematically searched in patients with ID when such discrepancies are observed.

\section{ACKNOWLEDGMENTS}

We are grateful to Doctors Bussel, Fellous, Fradelizi, Habibi, and Messing and to Miss L. Legrand for their help in various aspects of this study.

This work was supported, in part, by grant 27.76.59 from Institut National de la Santé et de la Recherche Médicale.

\section{REFERENCES}

1. Cooper, M. D., and M. Seligmann. 1977. B and T lymphocytes in immuno-deficiency and lymphoproliferative diseases. In $\mathrm{B}$ and $\mathrm{T}$ Cells in Immune Recognition. F. Loor and G. E. Roelants, editors. John Wiley \& Sons Ltd., London. 377-405.

2. Winchester, R. J., J. B. Winfield, F. Siegal, P. Wernet, Z. Bentwich, and H. G. Kunkel. 1974. Analyses of lymphocytes from patients with rheumatoid arthritis and systemic lupus erythematosus. Occurrence of interfering cold-reactive antilymphocyte antibodies. J. Clin. Invest. 54: 1082-1092.

3. Strickland, R. G., E. M. Friedler, C. A. Henderson, I. D. Wilson, and R. C. Williams. 1975. Serum lymphocytotoxins in inflammatory bowel disease. Studies of frequency and specificity for lymphocyte subpopulations. Clin. Exp. Immunol. 21: 384-393.

4. Kretschmer, R., C. S. August, F. S. Rosen, and C. A. Janeway. 1969. Recurrent infections, episodic lymphopenia and impaired cellular immunity. Further observations on "immunologic amnesia" in two siblings. N. Engl. J. Med. 281: 285-290.

5. Gelfand, E. W., H. Borel, A. I. Berkel, and F. S. Rosen. 1972. Auto-immunosuppression: recurrent infections associated with immunologic unresponsiveness in the presence of an auto-antibody to IgG. Clin. Immunol. Immunopathol. 1: 155-163.

6. Seligmann, M., J. L. Preud'homme, and J. C. Brouet. 1973. $B$ and $T$ cell markers in human proliferative blood diseases and primary immunodeficiencies, with special reference to membrane bound immunoglobulins. Transplant. Rev. 16: 85-113.

7. Terasaki, P. I., and J. D. McClelland. 1964. Micro- 
droplet assay of human serum cytotoxins. Nature (Lond.). 4: 998-1000.

8. Preud'homme, J. L., and S. Labaume. 1976. Detection of surface immunoglobulins on human cells by direct immunofluorescence. In In Vitro Methods in Cell-Mediated and Tumor Immunity. B. R. Bloom and J. R. Davids, editors. Academic Press, Inc., New York. 155-169.

9. Brouet, J. C., G. Flandrin, M. Sasportes, J. L. Preud'homme, and M. Seligmann. 1975. Chronic lymphocytic leukemia of $T$ cell origin. An immunological and clinical evaluation in eleven patients. Lancet. II: 890-893.

10. Galton, D. A. G., J. M. Goldmann, E. Wiltshaw, D. Catovsky, K. Henry, and G. J. Goldenberg. 1974. Prolymphocytic leukaemia. Br. J. Haematol. 27: 7-23.

11. Winchester, R. J., S. M. Fu, P. Wernet, H. G. Kunkel,
B. Dupont, and C. Jersild. 1975. Recognition by pregnancy serums of non-HL-A alloantigens selectively expressed on B lymphocytes. J. Exp. Med. 141: 924-929.

12. Billing, R., B. Rafizadeh, I. Drew, G. Hartman, R. Gale, and P. Terasaki. 1976. Human B-lymphocyte antigens expressed by lymphocytic and myelocytic leukemia cells. I. Detection by rabbit antisera. J. Exp. Med. 144: $167-178$.

13. Schlossman, S. F., L. Chess, R. E. Humphreys, and J. L. Strominger. 1976. Distribution of Ia like molecules on the surface of normal and leukemic human cells. Proc. Natl. Acad. Sci. U.S.A. 73: 1288-1292.

14. Winchester, R. J., C. Y. Wang, J. Halper, and T. Hoffman. 1976. Studies with B-cell allo- and hetero-antisera: parallel reactivity and special properties. Scand. J. Immunol. 5: 745-757. 